\title{
Characterization of neutral boron-silicon clusters using infrared spectroscopy: \\ The case of $\mathrm{Si}_{6} \mathrm{~B}$
}

Nguyen Xuan Truonga ${ }^{a}$, Marko Haertelt ${ }^{b}$, Bertram K.A. Jaeger ${ }^{a}$, Sandy Gewinner ${ }^{b}$, Wieland Schöllkopf ${ }^{b}$, André Fielicke ${ }^{a *}$, and Otto Dopfera*

a) Institut für Optik und Atomare Physik, Technische Universität Berlin, Hardenbergstraße 36, D-10623 Berlin, Germany

*) Email: fielicke@physik.tu-berlin.de, dopfer@physik.tu-berlin.de

b) Fritz-Haber-Institut der Max-Planck-Gesellschaft, Faradayweg 4-6, D-14195 Berlin, Germany

\begin{abstract}
Nano-size clusters are of great interest for understanding of fundamental properties and processes relevant for applied materials science such as heterogeneous catalysis. In this study, we present a newly developed dualtarget dual-laser ablation source, suitable for the production of binary clusters and their spectroscopic characterization. With the current design, an almost arbitrary mixing ratio can be achieved by altering different parameters such as the laser fluences. Boron and silicon targets are chosen for cluster production, illustrating the possibility to control the outcome ranging from pure boron over mixed $\mathrm{Sin}_{\mathrm{n}}$ to pure silicon clusters. As a test system, $\mathrm{Si}_{6} \mathrm{~B}$ clusters are characterized by means of infrared-ultraviolet two-color ionization (IR-UV2Cl) spectroscopy, combined with quantum chemical simulations. The most stable structure of $\mathrm{Si}_{6} \mathrm{~B}\left(\mathrm{C}_{\mathrm{s}},{ }^{2} \mathrm{~A}^{\prime}\right)$ predicted in our previous work is confirmed by the present experiment. Doping of $\mathrm{Si}$ with a single $\mathrm{B}$ atom has a drastic impact on the geometric, vibrational, and electronic properties.
\end{abstract}




\section{Introduction}

Nano-size silicon-based structures have attracted a lot of interest in the current miniaturization trend toward nanophotonics and nanoelectronics (e.g., [1-5]). Particularly, the understanding of material properties changing with size, composition, and charge plays an important role. It has been shown that nanostructures such as metal and semiconductor nanocrystals, quantum dots, and nanowires can be well described within the context of related isolated (gas-phase) atomic clusters [2, 6, 7]. As pure gas-phase silicon clusters are chemically reactive, doping with other elements has been considered as a solution in finding stable Si-based building blocks [8, 9]. With the discovery of a superconducting transition at about $40 \mathrm{~K}$ in $\mathrm{MgB}_{2}$ [10], there has been great interest in boron-doped materials as promising superconductors, including boron-doped diamond [11, 12], silicon [13], and silicon carbide [14-16]. In crystalline phases, doping of group IV elements with boron as the source of holedoping has been shown to induce superconductivity $[12,13,17]$. For sufficient boron doping ( 100 ppm), silicon becomes metallic [18] and superconducting at a boron concentration of several percent with a critical temperature of $T_{c} \approx 0.35 \mathrm{~K}$ [13]. Ab initio calculations combined with Raman measurements strongly suggest that doping is substitutional [13]. Interestingly, similar effects have also been predicted for small B-doped silicon clusters [19]. Efforts have been made to increase $T_{c}$ in B-doped silicon [16, 20, 21].

Studies on small B-doped silicon clusters are however rare, both in theory and experiment. For instance, heats of formation of gas-phase $\operatorname{Sin} B(n=1-3)$ were measured by mass spectrometry [22]. Density functional theory (DFT) calculations for $\mathrm{SiB}_{2}, \mathrm{Si}_{2} \mathrm{~B}$, and $\mathrm{Si}_{2} \mathrm{~B}_{2}$ found stable ring-like structures with strong $\pi$-bonding [23]. Anionic Sin $B^{-}$clusters $(n=1-6)$ formed by direct laser ablation from a mixed $B / S i$ sample were studied by mass spectrometry and DFT calculations [24]. In that work, $\mathrm{Si}_{6} \mathrm{~B}^{-}$was predicted to have $\mathrm{C}_{5 v}$ symmetry $\left({ }^{1} \mathrm{~A}_{1}\right)$, whereas its neutral counterpart was suggested to have $C_{s}$ symmetric geometry $\left({ }^{2} A\right.$ ') [25]. Recently, Tam et al. studied thermochemical parameters and the growth mechanism of $B$-doped silicon clusters $\left(\operatorname{Sin} B^{q}, n=1-10, q=0, \pm 1\right)$ using B3LYP, G4, and CCSD $(T)$ approaches [19]. The ground state structures predicted for the neutrals suggest a growth mechanism, in which each $\mathrm{Sin}_{\mathrm{n}} \mathrm{B}$ is formed by adding a $\mathrm{Si}$ atom to $\mathrm{Si}_{\mathrm{n}-1} \mathrm{~B}$ rather than adding $\mathrm{B}$ into $\mathrm{Si}_{\mathrm{n}}$. For $\mathrm{Si}_{8} \mathrm{~B}$, exohedral and endohedral structures become close in energy. Interestingly, pure boron clusters with sizes of up to 20 atoms have quasi-planar structures, while $\mathrm{SiB}_{7}$ was predicted to have a $3 \mathrm{D}$ structure [26], indicating the importance of a single dopant atom on the properties of pure clusters. Surprisingly, no spectroscopic data are available for B-doped silicon clusters in any charge state. Here, we combine infraredultraviolet two-color ionization (IR-UV2CI) spectroscopy [27] with quantum chemical simulations to determine the structure of $\mathrm{Si} 6 \mathrm{~B}$, a strategy recently applied to a variety of (doped) silicon clusters [25, 27-30].

Due to the high melting point of boron $\left(>2000^{\circ} \mathrm{C}\right)$, B-containing clusters are usually generated by laser ablation (see, e.g., [31, 32]). An exhaustive review of laser ablation sources has recently been provided by Duncan [33]. To produce mixed clusters, various approaches have been demonstrated, such as single targets of alloys [34], binary compounds [35-37], pressed mixed powders [38, 39], and dual-target (dual-laser) sources [40-44]. The dual-target dual-laser source designs allow for controlling the mixing ratios by changing the laser fluences, laser timing, and the rotation and/or translation speeds of the targets. Here, we describe a dual-target dual-laser ablation source developed for the production and spectroscopic measurement of binary clusters. We 
demonstrate that with this cluster source an almost arbitrary mixing ratio between the different components can be achieved. As an example for the spectroscopic characterization of the clusters produced in this source, we apply the IR-UV2CI technique to neutral $\mathrm{Si} 6 \mathrm{~B}$ to determine its geometric structure, as suggested previously [25].

\section{Experimental and computational methods}

\subsection{Experimental setup}

The experiments are performed in a cluster beam experiment connected to a beamline of the Infrared Free Electron Laser at the Fritz Haber Institute of the Max Planck Society in Berlin, Germany (FHI FEL) [45, 46]. The cluster experiment has been described before [47] and is upgraded here with a new dual-target dual-laser ablation source (Fig. 1), with a design similar to the one reported by Banser et al. [44].

Mixed boron-silicon clusters $\left(\mathrm{Sin}_{\mathrm{n}} \mathrm{B}_{\mathrm{m}}\right)$ are produced by laser ablation of a silicon rod (natural isotopic abundance, ESPI metals, US) and an isotopically-enriched ${ }^{11} \mathrm{~B}$ rod $(99.5 \%$, Ceradyne, US; rod manufactured by RHP technology, Austria) within a pulsed flow of helium carrier gas. The two cylindrical rods with $6.2 \mathrm{~mm}$ diameter are symmetrically located on opposite sides of the central gas channel. This channel has a diameter of $6 \mathrm{~mm}$, and its volume can be adjusted with a teflon tube insert. Each rod is translated and rotated by a separate mechanism containing an in-vacuum stepper motor and a worm gear with a transmission ratio of 34:1 between motor and rod. This leads to a smooth and very slow movement of the target (few hours for one turn if required), always providing a fresh target. For ablation, two pulsed Nd:YAG lasers (Continuum Minilite, $10 \mathrm{~Hz}, 532 \mathrm{~nm}, \sim 5 \mathrm{~ns}$ ) are focused by lenses onto the targets. The two parallel laser beams from the backside of the source are deflected to hit each rod at an angle of $60^{\circ}$ with respect to the channel axis. This design ensures good spatial overlap of the ablation plumes, which is crucial for stable and controllable formation of binary clusters [43]. A solenoid valve (General Valve Series 9) is used to provide short helium carrier gas pulses (several $100 \mu \mathrm{s}$ ) at a backing pressure of about 4 bar. Through three-body collisions with carrier gas atoms, the atomic and molecular species contained in the ablation plasma are cooled down and form clusters. By tuning the laser fluence on each rod, either bare cluster distributions or binary cluster distributions with arbitrary mixing ratio can be produced (Fig. 2). Typically, pulse energies of about 4-6 $\mathrm{mJ}$ are used for $\mathrm{Si}$ and 5-8 $\mathrm{mJ}$ for $\mathrm{B}$. The source is extended with a thermally insulated thermalization and reaction channel of $3 \mathrm{~mm}$ inner diameter and $40 \mathrm{~mm}$ length. The inlet for reaction gases is not used in the experiments described here. The temperature of the channel can be stabilized between 80 and $400 \mathrm{~K}$ using a flow of liquid nitrogen and/or an electrical heater. In the experiments reported here it was set to $90 \mathrm{~K}$. At the channel exit, a converging/diverging nozzle of $\sim 1 \mathrm{~mm}$ aperture is mounted to induce further cooling [48].

The molecular beam is collimated by a skimmer with $2 \mathrm{~mm}$ diameter. Before passing through a $1 \mathrm{~mm}$ aperture located further downstream and held at $\sim 200 \mathrm{~V}$ to deflect charged clusters, the neutral $\operatorname{Sin}_{\mathrm{n}} \mathrm{B}$ clusters are irradiated with a counter-propagating IR laser beam from the FHI-FEL and then post-ionized after a delay of 30 $\mu$ s by an unfocused $F_{2}$ excimer laser (photon energy $E_{F 2}=7.87 \mathrm{eV}$ ) in the extraction zone of a reflectron time-of- 
flight mass spectrometer. The FHI FEL can deliver pulsed radiation in the wavelength range from 3.5 to $48 \mu \mathrm{m}$, with up to $100 \mathrm{~mJ}$ within a macropulse of $\sim 7 \mu$ s duration at about $0.4-1 \%$ full width at half maximum (FWHM) bandwidth. In our experiments an electron beam energy of $26 \mathrm{MeV}$ is used, providing access to a spectral range of $420-1100 \mathrm{~cm}^{-1}$. If the frequency of the FEL radiation is resonant with an IR active mode of a specific cluster, it can absorb IR photons followed by rapid intracluster vibrational energy redistribution, and thereby its internal energy increases. The ionization efficiency usually follows a S-curve behavior as a function of excitation energy, with a slope depending on the Franck-Condon factor for ionization [49]. An increase in the internal energy of the cluster upon IR absorption therefore results in an enhancement of the ionization yield. An IR-UV2CI spectrum is obtained from the relative ionization enhancement normalized by the IR photon flux as a function of the IR laser frequency $[25,50,51]$, which closely reflects the linear vibrational absorption spectrum of the neutral cluster.

\subsection{Computational method}

Quantum chemical calculations are performed to aid in the structural assignment and to give additional insight into electronic properties of the clusters. The most stable $\mathrm{Si}_{6} \mathrm{~B}$ structures are found with a genetic algorithm (GA) [52] coupled with DFT calculations, denoted as GA-DFT. Briefly, the GA-DFT approach starts with an initial population consisting of 32 candidate structures (individuals). Candidate structures are created by randomly distributing the atoms within a sphere with a radius of $1.9 \AA\left(r \approx r_{0} n^{1 / 3}, n=7, r_{0}=1 \AA\right)$. For each structure, the total energy obtained from local optimization at the RI-BP86/def-SVP level (TURBOMOLE V6.3.1 [53]) serves as the corresponding fitness value. After each generation, a new population is formed by tournament selection and subsequent modifications through crossover $\left(p_{\text {cross }}=0.6\right)$ and mutation $\left(p_{\text {mut }}=0.1\right)$ operators $[54,55]$. Typically, up to a thousand candidate structures are evaluated. The first 20 non-equivalent low-energy isomers are then tightly optimized at the TPSS-D3/cc-pVTZ, B3LYP-D3/cc-pVTZ, and G4 levels (GAUSSIAN 09 [56]). At these levels, also IR spectra, vertical ionization energies (VIE), and natural bond orbital (NBO) populations are calculated. Relative energies are corrected for zero-point vibrational energies. No scaling factor is employed for vibrational frequencies [51]. The theoretical IR absorption stick spectra are convoluted with a Gaussian profile with $\mathrm{FWHM}=20 \mathrm{~cm}^{-1}$. If not stated otherwise, the optimized parameters obtained at the TPSS level are given, while the B3LYP-D3 values are additionally given in parentheses.

\section{Results and discussion}

Parts of the mass distributions obtained by near-threshold photoionization of neutral clusters using the $F_{2}$ laser alone are shown in Fig. 2 for the mass range m/z 100-300. Almost arbitrary mixing ratios of $\mathrm{Sin}_{n} \mathrm{~B}_{\mathrm{m}}$ clusters can be achieved by just altering the laser pulse energies used for the ablation of the two targets. Pure $\mathrm{Sin}_{n}$ clusters $\left(n \leq 20\right.$, Fig. $2 a$ ) or pure $B_{m}$ clusters ( $m \leq 30$, Fig. $2 d$ ) are readily produced by ablation from just a single target, with observed distributions similar to what has been reported before $[31,57]$. These distributions mainly reflect the variation in the ionization energies with cluster size. By increasing the laser pulse energy on the second target, 
doping with single atoms or higher mixing ratios can be achieved in a controlled way. As examples, distributions of Si-rich $\mathrm{Si}_{n} \mathrm{~B}_{m}$ clusters containing typically up to $\mathrm{m}=3$ boron atoms and B-rich $\mathrm{Si}_{n} \mathrm{~B}_{m}$ clusters containing up to $\mathrm{n}=2$ silicon atoms are shown in Fig. $2 \mathrm{~b}$ and $2 \mathrm{c}$, respectively. Larger $\mathrm{Sin}_{n} \mathrm{~B}_{\mathrm{m}}$ clusters $(\mathrm{n}+\mathrm{m} \geq 20)$ can also be generated. However, the isotope distribution of $28,29,30 \mathrm{Si}$ complicates the assignment of the mass spectra. Note that a ${ }^{11} \mathrm{~B}$-enriched boron target is used here to simplify the isotope pattern. In addition to neutral clusters, the laser ablation source also produces charged, i.e. cationic and anionic, species.

Figure 3 illustrates the enhancement of certain ion signals when in addition to the UV pulse also IR radiation is applied. At an IR frequency of $531 \mathrm{~cm}^{-1}$, about $70 \%$ enhancement of the $\mathrm{Si}_{6} \mathrm{~B}^{+}$ion intensity is observed for all isotopologues, indicating a resonant IR active vibrational mode of $\mathrm{Si}_{6} \mathrm{~B}$ at this frequency. By scanning the IR frequency and recording the ionization enhancement of $\mathrm{Si}_{6} \mathrm{~B}^{+}$, an IR-UV2Cl spectrum of the neutral cluster is obtained.

The IR-UV2CI spectrum recorded for $\mathrm{Si}_{6} \mathrm{~B}$ in the $420-1000 \mathrm{~cm}^{-1}$ range is compared in Fig. 4 to linear IR absorption spectra calculated for the five lowest-energy structures (6a-6e). These $\mathrm{Si}_{6} \mathrm{~B}$ isomers are found with the GA-DFT approach and are further optimized at the TPSS-D3/cc-pVTZ, B3LYP-D3/cc-pVTZ, and G4 levels. Their structural, vibrational, and energetic parameters are available in the Supporting Information (SI). Most of the computational results have already been provided in our recent work [25] and support the previous study of Tam et al. [19]. Generally, the three used methods agree in predicting the most stable structure (6a), while for the substantially higher-energy structures $(\geq 30 \mathrm{~kJ} / \mathrm{mol}$ ) slight differences in their relative energies are observed. In addition to the molecular symmetries and electronic ground states (Fig. 4), the VIE values (TPSS level) are also shown to judge the possibility to detect the various isomeric clusters with the IR-UV2CI technique.

The most stable structure $\mathbf{6 a}$ of $\mathrm{Si}_{6} \mathrm{~B}$ is a distorted pentagonal bipyramid $\left(\mathrm{C}_{\mathrm{s}},{ }^{2} \mathrm{~A}^{\prime}\right)$ formed by substituting a $\mathrm{Si}$ atom at an apex of the most stable $\mathrm{Si}_{7}$ structure $\left(\mathrm{D}_{5 \mathrm{~h}},{ }^{1} \mathrm{~A}_{1}{ }^{\prime}\right)$ by a $B$ atom. Its VIE value of $8.0 \mathrm{eV}$ is similar to $\mathrm{E}_{\mathrm{F} 2}$ $(7.87 \mathrm{eV})$, indicating that $\mathbf{6} \mathbf{a}$ can readily be detected if present in the molecular beam. According to the TPSS calculations, the next stable structure $6 \mathbf{b}$ with $\mathrm{C}_{2 \mathrm{v}}\left({ }^{2} \mathrm{~A}_{1}\right)$ symmetry is $42 \mathrm{~kJ} / \mathrm{mol}$ higher in energy and formed by $\mathrm{B}$ substitution of a $\mathrm{Si}$ atom at the equator of the $\mathrm{Si}_{7}$ pentagonal bipyramid. These most favorable locations for $\mathrm{B}$ doping in $\mathrm{Si}_{7}$ have previously been observed also for other dopant atoms, e.g., in $\mathrm{Si}_{6} \mathrm{C}\left(\mathrm{C}_{5 \mathrm{v}}\right)$ [25], $\mathrm{Si}_{6} \mathrm{~V}\left(\mathrm{C}_{2 \mathrm{v}}\right)$, and $\mathrm{Si}_{6} \mathrm{Mn}\left(\mathrm{C}_{2 \mathrm{v}}\right)$ [58]. The other high-lying $\mathrm{Si}_{6} \mathrm{~B}$ structures $\mathbf{6 c - 6 e}$ have a very similar topology, but differ in the location of the $B$ atom. Except for $6 \mathbf{a}$, all structures have predicted VIE values (7.0-7.2 eV) well below $E_{F 2}$, and thus would be, in case of their presence, more difficult to detect using the IR-UV2CI technique.

Within the investigated spectral range of $450-1000 \mathrm{~cm}^{-1}$, the IR-UV2CI spectrum of $\mathrm{Si}_{6} \mathrm{~B}$ exhibits three distinct bands centered at 430 (A), 535 (B), and 661 (C) $\mathrm{cm}^{-1}$, which can readily be assigned to vibrational transitions of the most stable structure $6 \mathbf{a}$. Its calculated linear IR spectrum agrees well with the observed IR-UV2CI spectrum with respect to both the position and relative IR intensity of the transitions. Specifically, the weak band $\mathbf{A}$ is assigned to the equatorial breathing mode (a') predicted at $421 \mathrm{~cm}^{-1}$. Band $\mathbf{B}$ is attributed to the axial breathing mode (a') calculated at $540 \mathrm{~cm}^{-1}$. Finally, the intense and somewhat broader band $\mathbf{C}$ is interpreted as the two overlapping axial bending fundamentals (a" and a') predicted at 649 and $663 \mathrm{~cm}^{-1}$, respectively. Its larger width 
(FWHM $\left.=52 \mathrm{~cm}^{-1}\right)$ compared to those of band $\mathbf{A}$ and $\mathbf{B}\left(\sim 22 \mathrm{~cm}^{-1}\right)$ is consistent with its interpretation of two unresolved transitions split by $24 \mathrm{~cm}^{-1}$. In general, the deviations of $9,5,12$, and $2 \mathrm{~cm}^{-1}$ are well within the spectral resolution of the experimental approach. No spectral signatures of the less stable isomers $6 \mathbf{b}-6 \mathbf{e}$ are detected in the measured IR-UV2CI spectrum, consistent with their high relative energy (and their low VIE values).

Interestingly, it is found that the five equivalent minima of $\mathrm{Si}_{6} \mathrm{~B}$ in the $\mathbf{6 a}$ structure are separated by a very low barrier of only $0.7 \mathrm{~kJ} / \mathrm{mol}$ at a $\mathrm{C}_{\mathrm{s}}$ symmetric transition state $\left({ }^{2} \mathrm{~A}\right.$ ", Figure S2), indicating fluxional behavior even at low temperature. However, it appears that the calculated harmonic spectrum reproduces the experimental one very well indicating an only minor role of anharmonic effects. Notably, the real part of the IR spectrum calculated for the transition state is nearly identical to the one of $6 a$. Within the DFT calculations a $\mathrm{C}_{5 v}{ }$ symmetric ${ }^{2} \mathrm{E}_{2}$ state is found $16.9 \mathrm{~kJ} / \mathrm{mol}$ higher in energy than $\mathbf{6 a}$ but is expected to undergo symmetry-lowering due to the JahnTeller effect.

It is instructive to compare the properties of $\mathrm{Si}_{6} \mathrm{~B}$ with those of $\mathrm{Si} 7[25,27]$ to evaluate the effects of $\mathrm{Si} \rightarrow \mathrm{B}$ substitution on the geometric, vibrational, and electronic properties. To this end, Figure 5 shows the vibrational spectra and geometric structures of $\mathrm{Si}_{7}$ and its B-doped counterpart $\mathrm{Si}_{6} \mathrm{~B}$. At the first glance, the $\mathrm{D}_{5 \mathrm{~h}}$ symmetry of the closed-shell $\mathrm{Si}_{7}$ pentagonal bipyramid $\left({ }^{1} \mathrm{~A}_{1}{ }^{\prime}\right)$ is reduced to $\mathrm{C}_{\text {s }}$ symmetry for the open-shell $\mathrm{Si}_{6} \mathrm{~B}$ cluster $\left({ }^{2} \mathrm{~A}^{\prime}\right)$. Further, doping with a $\mathrm{B}$ atom makes $\mathrm{Si}_{6} \mathrm{~B}$ more compact in shape compared to $\mathrm{Si}_{7}$, due to the stronger and shorter $\mathrm{Si}-\mathrm{B}$ bonds as compared to the Si-Si bonds. Specifically, in the five-membered $\mathrm{Si}$ ring, the averaged SiSi bond length is 2.367 (2.382) $\AA$ for $\mathrm{Si} 6 \mathrm{~B}$ and 2.504 (2.515) $\AA$ for Siz. In addition, the distance between the apex atoms is 2.270 (2.294) $\AA$ for $\mathrm{Si}_{6} \mathrm{~B}$, much shorter than that for $\mathrm{Si}_{7}(2.529$ (2.570) $\AA$ ). Boron doping has also a substantial impact on the appearance of the IR spectrum. In general, symmetry reduction produces a richer spectrum due to a larger number of IR allowed transitions, and the lighter mass of $B$ and the larger force constants of the B-Si bonds result in higher vibrational frequencies. The bending mode of the axial atoms at 418 $\mathrm{cm}^{-1}\left(\mathrm{e}_{1}{ }^{\prime}\right)$ for $\mathrm{Si}_{7}$ is split and shifted to 649 (a") and $663 \mathrm{~cm}^{-1}$ (a') for $\mathrm{Si}_{6} \mathrm{~B}$. The IR-forbidden breathing mode of $\mathrm{Si}_{7}$ at $437 \mathrm{~cm}^{-1}$ (a $\left.1_{1}^{\prime}\right)$ becomes strongly IR-active for $\mathrm{Si}_{6} \mathrm{~B}$ and shifts to $540 \mathrm{~cm}^{-1}\left(\mathrm{a}^{\prime}\right)$. The NBO population analysis [59] shows that a large negative charge of -1.41 e $(-1.45 e)$ is located on the electron-accepting $B$ dopant atom, while the corresponding positive charge is nearly equally distributed over all $\mathrm{Si}$ atoms in the five-membered ring. Only an amount of $0.01 e(0.03 e)$ is located at the $\mathrm{Si}$ atom at the apex. In terms of electronic transitions, $\mathrm{Si}_{6} \mathrm{~B}$ shows the first allowed transition in the IR range $(0.52 \mathrm{eV})$, whereas it is at $3.35 \mathrm{eV}$ for Si7 [25].

\section{Conclusions}

Binary boron-silicon clusters $\left(\mathrm{Sin}_{\mathrm{n}} \mathrm{B}_{\mathrm{m}}\right)$ are generated in a new dual-target dual-laser ablation source and characterized by means of mass spectrometry, IR-UV2 $\mathrm{Cl}$ spectroscopy, and quantum chemical simulations. By altering the laser fluences on the target rods, either Si-rich or B-rich clusters can be produced. With a predicted VIE value slightly higher than the $\mathrm{F}_{2}$ laser photon energy, $\mathrm{Si}_{6} \mathrm{~B}$ is a suitable cluster for testing the capability of the new cluster source for coupling with IR-UV2Cl spectroscopy. Three vibrational bands of $\mathrm{Si}_{6} \mathrm{~B}$ are observed 
experimentally, in agreement with the calculated vibrational modes of the most stable isomer $\left(6 \mathbf{6}, C_{s},{ }^{2} A^{\prime}\right)$. Calculated VIE values of the five lowest-energy $\mathrm{Si}_{6} \mathrm{~B}$ isomers suggest that only $\mathbf{6 a}$ may be detected by our IR$\mathrm{UV} 2 \mathrm{Cl}$ setup under the present experimental conditions. However, as all these less stable isomers (6b-6e) are predicted to be rather high in energy, they are not expected to be produced in the cluster source. Comparing to $\mathrm{Si}_{7}, \mathrm{Si}_{6} \mathrm{~B}$ is more compact in shape and exhibits optical absorption at much lower frequency (IR range). In general, our setup can be used to study binary clusters of metals, metalloids, and semiconductor elements, which is currently of great interest for searching novel cluster building blocks.

\section{Acknowledgements}

This work was supported by the Deutsche Forschungsgemeinschaft within the research unit FOR 1282 (DO 729/5, FI 893/4). We thank Philipp Jäger and Alex P. Woodham for their support in the experiments.

\section{References}

[1] M.J. Schoning, F. Ronkel, M. Crott, M. Thust, J.W. Schultze, P. Kordos, H. Luth, Miniaturization of potentiometric sensors using porous silicon microtechnology, Electrochim Acta, 42 (1997) 3185-3193.

[2] R.N. Barnett, U. Landman, Cluster-derived structures and conductance fluctuations in nanowires, Nature, 387 (1997) 788-791.

[3] K. Tomioka, M. Yoshimura, T. Fukui, A III-V nanowire channel on silicon for high-performance vertical transistors, Nature, 488 (2012) 189-192.

[4] T.M. Fu, X.J. Duan, Z. Jiang, X.C. Dai, P. Xie, Z.G. Cheng, C.M. Lieber, Sub-10-nm intracellular bioelectronic probes from nanowire-nanotube heterostructures, Proc. Natl. Acad. Sci. U.S.A., 111 (2014) 1259-1264.

[5] N.M. Ravindra, The drive for further miniaturization: Silicon nanoelectronics, Jom-Us, 57 (2005) 14-15.

[6] W. de Heer, The physics of simple metal clusters: experimental aspects and simple models, Rev. Mod. Phys., 65 (1993) 611-676.

[7] T.P. Martin, NATO, Large clusters of atoms and molecules, Kluwer, Dordrecht, 1996.

[8] P. Melinon, B. Masenelli, F. Tournus, A. Perez, Playing with carbon and silicon at the nanoscale, Nat Mater, 6 (2007) 479-490.

[9] C. Ray, M. Pellarin, J.L. Lerme, J.L. Vialle, M. Broyer, X. Blase, P. Melinon, P. Keghelian, A. Perez, Synthesis and structure of silicon-doped heterofullerenes, Phys. Rev. Lett., 80 (1998) 5365-5368.

[10] J. Nagamatsu, N. Nakagawa, T. Muranaka, Y. Zenitani, J. Akimitsu, Superconductivity at $39 \mathrm{~K}$ in magnesium diboride, Nature, 410 (2001) 63-64. 
[11] E.A. Ekimov, V.A. Sidorov, E.D. Bauer, N.N. Mel'nik, N.J. Curro, J.D. Thompson, S.M. Stishov, Superconductivity in diamond, Nature, 428 (2004) 542-545.

[12] T. Yokoya, T. Nakamura, T. Matsushita, T. Muro, Y. Takano, M. Nagao, T. Takenouchi, H. Kawarada, T. Oguchi, Origin of the metallic properties of heavily boron-doped superconducting diamond, Nature, 438 (2005) 647-650.

[13] E. Bustarret, C. Marcenat, P. Achatz, J. Kacmarcik, F. Levy, A. Huxley, L. Ortega, E. Bourgeois, X. Blase, D. Debarre, J. Boulmer, Superconductivity in doped cubic silicon, Nature, 444 (2006) 465-468.

[14] T. Muranaka, Y. Kikuchi, T. Yoshizawa, N. Shirakawa, J. Akimitsu, Superconductivity in carrier-doped silicon carbide, Sci. Technol. Adv. Mat., 9 (2008) 044204.

[15] M. Kriener, Y. Maeno, T. Oguchi, Z.A. Ren, J. Kato, T. Muranaka, J. Akimitsu, Specific heat and electronic states of superconducting boron-doped silicon carbide, Phys. Rev. B., 78 (2008) 024517.

[16] Z.A. Ren, J. Kato, T. Muranaka, J. Akimitsu, M. Kriener, Y. Maeno, Superconductivity in boron-doped SiC, J. Phys. Soc. Jpn, 76 (2007) 103710.

[17] K. lakoubovskii, Superconductivity in covalent semiconductors, Cent. Eur. J. Phys., 7 (2009) 654-662.

[18] P.H. Dai, Y.H. Zhang, M.P. Sarachik, Critical Conductivity Exponent for Si-B, Phys. Rev. Lett., 66 (1991) 1914-1917.

[19] N.M. Tam, T.B. Tai, M.T. Nguyen, Thermochemical Parameters and Growth Mechanism of the BoronDoped Silicon Clusters, $\operatorname{Sin}_{n} B^{q}$ with $n=1-10$ and $q=-1,0,+1$, J. Phys. Chem. C, 116 (2012) 20086-20098.

[20] N.T. Bagraev, W. Gehlhoff, L.E. Klyachkin, A.M. Malyarenko, V.V. Romanov, S.A. Rykov, Superconductivity in silicon nanostructures, Physica C, 437-38 (2006) 21-24.

[21] A. Grockowiak, T. Klein, H. Cercellier, F. Levy-Bertrand, X. Blase, J. Kacmarcik, T. Kociniewski, F. Chiodi, D. Debarre, G. Prudon, C. Dubois, C. Marcenat, Thickness dependence of the superconducting critical temperature in heavily doped Si:B epilayers, Phys. Rev. B., 88 (2013) 064508.

[22] R. Viswanathan, R.W. Schmude, K.A. Gingerich, Thermochemistry of BSi(g), BSi 2 (g), and BSi 3 (g), J. Phys. Chem., 100 (1996) 10784-10786.

[23] R. Davy, E. Skoumbourdis, D. Dinsmore, Structure, energies, vibrational spectra and reactions of the boronsilicon cluster molecules $\mathrm{B}_{2} \mathrm{Si}, \mathrm{BSi}_{2}$ and $\mathrm{B}_{2} \mathrm{Si}_{2}$, Mol. Phys., 103 (2005) 611-619.

[24] Z. Sun, Z. Yang, Z. Gao, Z.C. Tang, Experimental and theoretical investigation on binary semiconductor clusters of B/Si and Al/Si, Rapid Commun. Mass. Sp., 21 (2007) 792-798.

[25] N.X. Truong, M. Savoca, D.J. Harding, A. Fielicke, O. Dopfer, Vibrational spectra and structures of neutral $\mathrm{Si}_{6} \mathrm{X}$ clusters $(\mathrm{X}=\mathrm{Be}, \mathrm{B}, \mathrm{C}, \mathrm{N}, \mathrm{O})$, Phys. Chem. Chem. Phys., 16 (2014) 22364-22372. 
[26] T.B. Tai, P. Kadlubanski, S. Roszak, D. Majumdar, J. Leszczynski, M.T. Nguyen, Electronic Structures and Thermochemical Properties of the Small Silicon-Doped Boron Clusters $\mathrm{B}_{n} \mathrm{Si}(\mathrm{n}=1-7)$ and Their Anions, Chem. Phys. Chem., 12 (2011) 2948-2958.

[27] A. Fielicke, J.T. Lyon, M. Haertelt, G. Meijer, P. Claes, J. de Haeck, P. Lievens, Vibrational spectroscopy of neutral silicon clusters via far-IR-VUV two color ionization, J Chem Phys, 131 (2009) 171105.

[28] Y.J. Li, N.M. Tam, P. Claes, A.P. Woodham, J.T. Lyon, V.T. Ngan, M.T. Nguyen, P. Lievens, A. Fielicke, E. Janssens, Structure Assignment, Electronic Properties, and Magnetism Quenching of Endohedrally Doped Neutral Silicon Clusters, $\mathrm{Sin}$ Co ( $\mathrm{n}=10-12)$, J. Phys. Chem. A, 118 (2014) 8198-8203.

[29] M. Haertelt, J.T. Lyon, P. Claes, J. de Haeck, P. Lievens, A. Fielicke, Gas-phase structures of neutral silicon clusters, J Chem Phys, 136 (2012) 064301.

[30] M. Savoca, A. Lagutschenkov, J. Langer, D.J. Harding, A. Fielicke, O. Dopfer, Vibrational Spectra and Structures of Neutral $\mathrm{Si}_{m} \mathrm{C}_{n}$ Clusters $(m+n=6)$ : Sequential Doping of Silicon Clusters with Carbon Atoms, J. Phys. Chem. A, 117 (2013) 1158-1163.

[31] C. Romanescu, D.J. Harding, A. Fielicke, L.S. Wang, Probing the structures of neutral boron clusters using infrared/vacuum ultraviolet two color ionization: $B_{11}, B_{16}$, and B17, J Chem Phys, 137 (2012) 014317.

[32] C. Romanescu, T.R. Galeev, A.P. Sergeeva, W.L. Li, L.S. Wang, A.I. Boldyrev, Experimental and computational evidence of octa- and nona-coordinated planar iron-doped boron clusters: $\mathrm{Fe}(\mathrm{c}) \mathrm{B}_{8}{ }^{-}$and $\mathrm{Fe}(\mathrm{c}) \mathrm{B}_{9}{ }^{-}$, J. Organomet. Chem., 721 (2012) 148-154.

[33] M.A. Duncan, Invited review article: laser vaporization cluster sources, Rev. Sci. Instrum., 83 (2012) 041101.

[34] R.G. Wheeler, K. Laihing, W.L. Wilson, J.D. Allen, R.B. King, M.A. Duncan, Neutral Gas-Phase Analogs of Condensed-Phase Post-Transition-Metal Cluster lons - Laser Vaporization and Photoionization of Sn/Bi and $\mathrm{Pb} / \mathrm{Sb}$ Alloys, J. Am. Chem. Soc., 108 (1986) 8101-8102.

[35] T. Kimura, T. Sugai, H. Shinohara, Production and characterization of boron- and silicon-doped carbon clusters, Chem. Phys. Lett., 256 (1996) 269-273.

[36] A. Nakajima, T. Taguwa, K. Nakao, M. Gomei, R. Kishi, S. Iwata, K. Kaya, Photoelectron spectroscopy of silicon-carbon cluster anions, Surf. Rev. Lett., 3 (1996) 411-415.

[37] M. Pellarin, C. Ray, P. Melinon, J. Lerme, J.L. Vialle, P. Keghelian, A. Perez, M. Broyer, Silicon-carbon mixed clusters, Chem. Phys. Lett., 277 (1997) 96-104.

[38] H.T. Deng, B.C. Guo, K.P. Kerns, A.W. Castleman, Formation and Stability of Metallocarbohedrenes $\mathrm{Tix}_{\mathrm{x}} \mathrm{M}_{\mathrm{y}} \mathrm{C}_{12}(\mathrm{x}+\mathrm{y}=8, \mathrm{M}=\mathrm{Nb}, \mathrm{Ta}, \mathrm{Y}$, and Si), Int. J. Mass. Spectrom., 138 (1994) 275-281.

[39] C. Romanescu, T.R. Galeev, W.L. Li, A.I. Boldyrev, L.S. Wang, Aromatic Metal-Centered Monocyclic Boron Rings: $\mathrm{Co}(\mathrm{c}) \mathrm{B}_{8}{ }^{-}$and $\mathrm{Ru}(\mathrm{c}) \mathrm{B}_{9}{ }^{-}$, Angew. Chem. Int. Edit., 50 (2011) 9334-9337. 
[40] S. Nonose, Y. Sone, K. Onodera, S. Sudo, K. Kaya, Structure and Reactivity of Bimetallic Con $V_{m}$ Clusters, J. Phys. Chem., 94 (1990) 2744-2746.

[41] R.L. Wagner, W.D. Vann, A.W. Castleman, A technique for efficiently generating bimetallic clusters, Rev. Sci. Instrum., 68 (1997) 3010-3013.

[42] W. Bouwen, P. Thoen, F. Vanhoutte, S. Bouckaert, F. Despa, H. Weidele, R.E. Silverans, P. Lievens, Production of bimetallic clusters by a dual-target dual-laser vaporization source, Rev. Sci. Instrum., 71 (2000) 54-58.

[43] K. Koyasu, J. Atobe, M. Akutsu, M. Mitsui, A. Nakajima, Electronic and geometric stabilities of clusters with transition metal encapsulated by silicon, J. Phys. Chem. A, 111 (2007) 42-49.

[44] D. Banser, M. Schnell, J.U. Grabow, E.J. Cocinero, A. Lesarri, J.L. Alonso, The internuclear potential, electronic structure, and chemical bond of tellurium selenide, Angew. Chem. Int. Edit., 44 (2005) 6311-6315.

[45] W. Schöllkopf, S. Gewinner, H. Junkes, A. Paarmann, G. von Helden, H. Bluem, A.M.M. Todd, The new IR and THz FEL Facility at the Fritz Haber Institute in Berlin, in: SPIE Conference Advances in X-ray Free-Electron Lasers Instrumentation III, Sandra G. Biedron, Editor, Proc. of SPIE 9512, 2015, 95121L.

[46] W. Schöllkopf, S. Gewinner, W. Erlebach, H. Junkes, A. Liedke, G. Meijer, A. Paarmann, G. von Helden, H. Bluem, D. Dowell, R. Lange, J. Rathke, A.M.M. Todd, L.M. Young, U. Lehnert, P. Michel, W. Seidel, R. Wünsch, S.C. Gottschalk, The new IR FEL Facility at the Fritz-Haber-Institut in Berlin, in: Proc. of the 36th Free Electron Laser Conference, Basel, Switzerland, 2014, pp. 629-634.

[47] A. Fielicke, G. von Helden, G. Meijer, Far-infrared spectroscopy of isolated transition metal clusters, Eur. Phys. J. D, 34 (2005) 83-88.

[48] H. Pauly, Atom, molecule, and cluster beams I basic theory, production and detection of thermal energy beams, Springer, Berlin, 2000.

[49] A.S. Sudbo, P.A. Schulz, D.J. Krajnovich, Y.T. Lee, Y.R. Shen, Photo-Ionization Study of MultiphotonExcited $S_{6}$ in a Molecular-Beam, Opt. Lett., 4 (1979) 219-221.

[50] M. Haertelt, A. Fielicke, G. Meijer, K. Kwapien, M. Sierka, J. Sauer, Structure determination of neutral MgO clusters-hexagonal nanotubes and cages, Phys. Chem. Chem. Phys., 14 (2012) 2849-2856.

[51] N.X. Truong, M. Savoca, D.J. Harding, A. Fielicke, O. Dopfer, Vibrational spectra and structures of $\mathrm{Sin}_{\mathrm{n}} \mathrm{C}$ clusters $(n=3-8)$, Phys. Chem. Chem. Phys., 17 (2015) 18961-18970.

[52] M. Wall, GAlib: A C++ Genetic Algorithm Library. Available from: http://lancet.mit.edu/ga.

[53] TURBOMOLE V6.3 2011, a development of University of Karlsruhe and Forschungszentrum Karlsruhe GmbH, 1989-2007, TURBOMOLE GmbH, since 2007. Available from http://www.turbomole.com.

[54] D.E. Goldberg, Genetic algorithms in search, optimization, and machine learning, Addison-Wesley, Reading, Mass. ; Wokingham, 1989. 
[55] J.H. Holland, Adaptation in natural and artificial systems : an introductory analysis with applications to biology, control, and artificial intelligence, 1st MIT Press ed., MIT Press, 1992.

[56] M.J. Frisch, G.W. Trucks, H.B. Schlegel, G.E. Scuseria, M.A. Robb, J.R. Cheeseman, G. Scalmani, V. Barone, B. Mennucci, G.A. Petersson, H. Nakatsuji, M. Caricato, X. Li, H.P. Hratchian, A.F. Izmaylov, J. Bloino, G. Zheng, J.L. Sonnenberg, M. Hada, M. Ehara, K. Toyota, R. Fukuda, J. Hasegawa, M. Ishida, T. Nakajima, Y Honda, O. Kitao, H. Nakai, T. Vreven, J.A. Montgomery, Jr., J.E. Peralta, F. Ogliaro, M. Bearpark, J.J. Heyd, E. Brothers, K.N. Kudin, V.N. Staroverov, R. Kobayashi, J. Normand, K. Raghavachari, A. Rendell, J.C. Burant, S.S. Iyengar, J. Tomasi, M. Cossi, N. Rega, N.J. Millam, M. Klene, J.E. Knox, J.B. Cross, V. Bakken, C. Adamo, J. Jaramillo, R. Gomperts, R.E. Stratmann, O. Yazyev, A.J. Austin, R. Cammi, C. Pomelli, J.W. Ochterski, R.L. Martin, K. Morokuma, V.G. Zakrzewski, G.A. Voth, P. Salvador, J.J. Dannenberg, S. Dapprich, A.D. Daniels, Ö. Farkas, J.B. Foresman, J.V. Ortiz, J. Cioslowski, D.J. Fox, Gaussian 09 Revision D.01, in, Gaussian Inc. Wallingford CT, 2009.

[57] D.J. Trevor, D.M. Cox, K.C. Reichmann, R.O. Brickman, A. Kaldor, lonizing Laser Intensity Dependence of the Silicon Cluster Photoionization Mass-Spectrum, J. Phys. Chem., 91 (1987) 2598-2601.

[58] P. Claes, V.T. Ngan, M. Haertelt, J.T. Lyon, A. Fielicke, M.T. Nguyen, P. Lievens, E. Janssens, The structures of neutral transition metal doped silicon clusters, $\operatorname{Sin} X(n=6-9 ; X=V, M n), J$ Chem Phys, 138 (2013) 194301.

[59] F.L. Weinhold, Clark R., Discovering Chemistry With Natural Bond Orbitals, John Wiley \& Sons, Inc., Canada, 2012. 


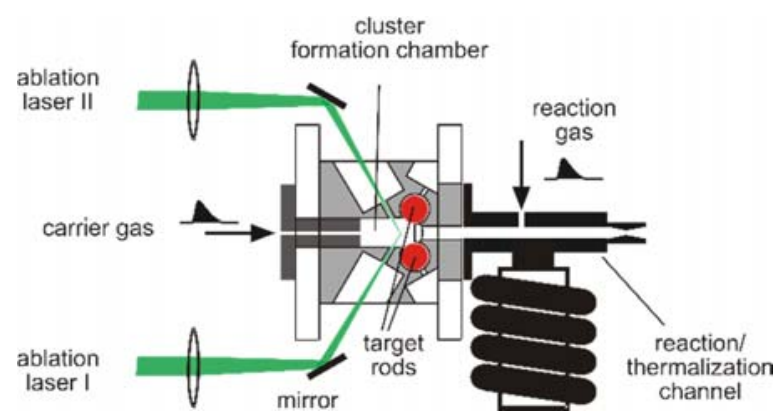

Figure 1. Schematic view of the dual-target dual-laser ablation source for the production of mixed $\mathrm{Sin}_{\mathrm{n}} \mathrm{m}$ clusters. 


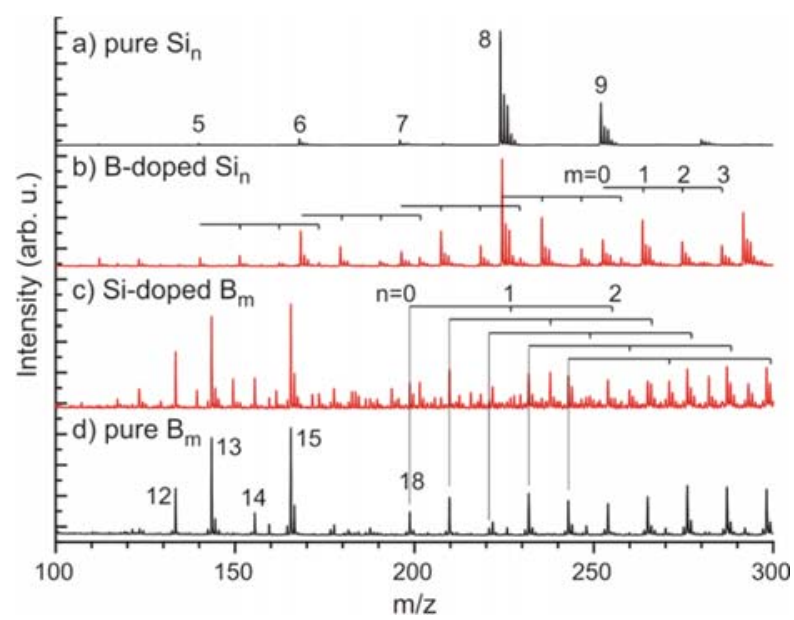

Figure 2. Typical mass spectra of $\mathrm{Sin}_{\mathrm{n}} \mathrm{B}_{\mathrm{m}}$ mixed clusters produced with the dual-target dual-laser ablation source. By altering the laser fluences, arbitrary mixing ratios of $\mathrm{Sin}_{\mathrm{n}} \mathrm{B}_{\mathrm{m}}$ clusters, i.e., from pure $\mathrm{Sin}_{n}$ and $\mathrm{B}_{\mathrm{m}}$ to $\mathrm{Si}$-rich and Brich $\mathrm{Si}_{n} \mathrm{~B}_{\mathrm{m}}$ can be achieved. The used laser pulse energies are $\mathrm{Si}_{\mathrm{ibl}} /{ }^{\mathrm{B}} \mathrm{E}_{\mathrm{abl}}=6 / 0 \mathrm{~mJ}(\mathrm{a}), 6 / 6 \mathrm{~mJ}(\mathrm{~b}), 6 / 8 \mathrm{~mJ}(\mathrm{c})$, and $0 / 8 \mathrm{~mJ}(\mathrm{~d})$. 


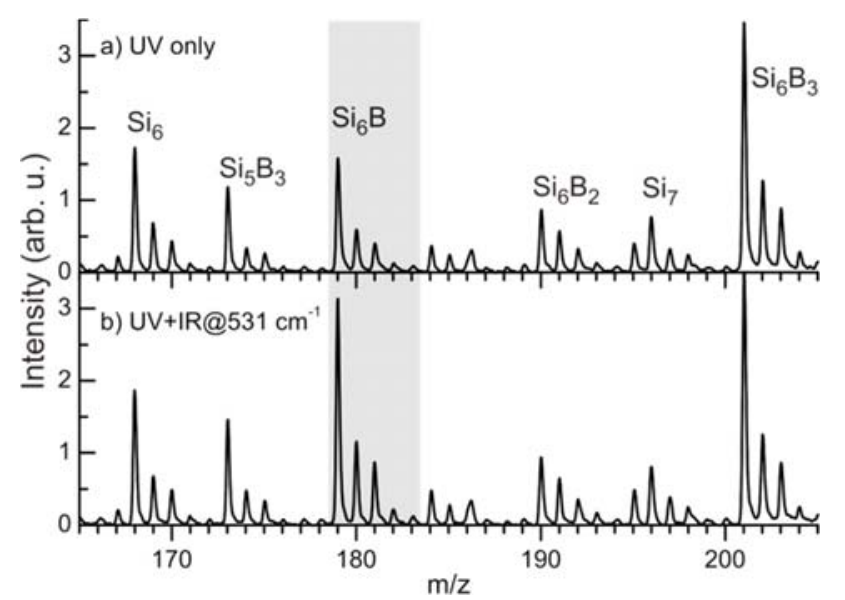

Figure 3. Mass spectra of $\mathrm{Sin}_{\mathrm{m}}$ clusters irradiated with a) UV laser only and b) UV and IR radiation at a frequency of $531 \mathrm{~cm}^{-1}$, showing a significant enhancement $(\sim 70 \%)$ of the $\mathrm{Si}_{6} \mathrm{~B}$ ion yield with the additional IR radiation. 


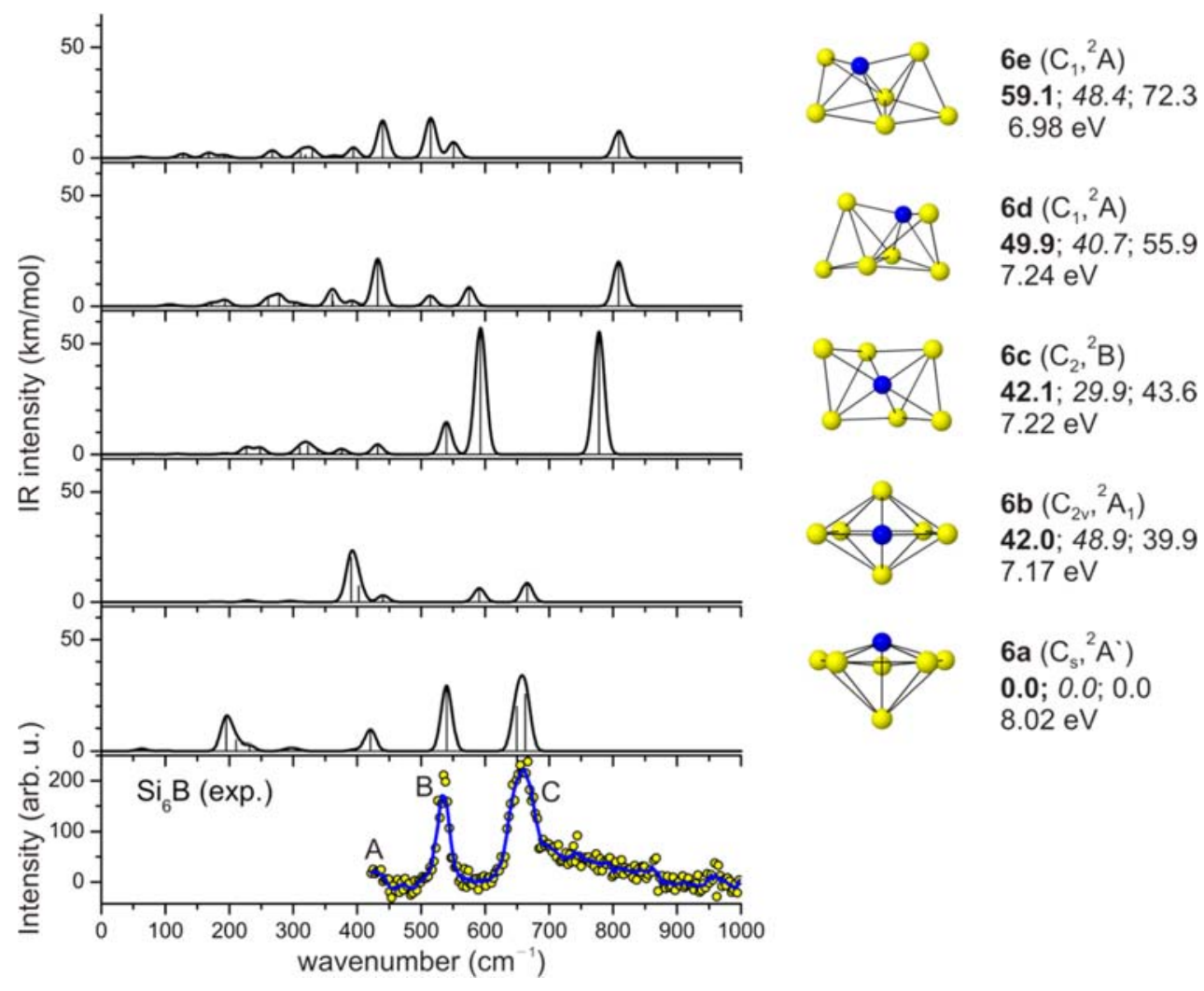

Figure 4. Comparison of the IR-UV2CI spectrum recorded for $\mathrm{Si}_{6} \mathrm{~B}$ with the vibrational spectra of the five lowestenergy structures 6a-6e calculated at the TPSS-D3/cc-pVTZ level. Experimental peak positions are 430 (A, onset), 535 (B), and 661 (C) $\mathrm{cm}^{-1}$. The relative energies obtained the TPSS-D3/cc-pVTZ, B3LYP-D3/cc-pVTZ, and $\mathrm{G} 4$ levels are given in $\mathrm{kJ} / \mathrm{mol}$ (left to right), along with point group symmetries, electronic states, and vertical ionization energies (VIE in eV) obtained at the TPSS-D3 level. Cartesian coordinates and vibrational spectra of the calculated structures are provided in the Supporting Information. 


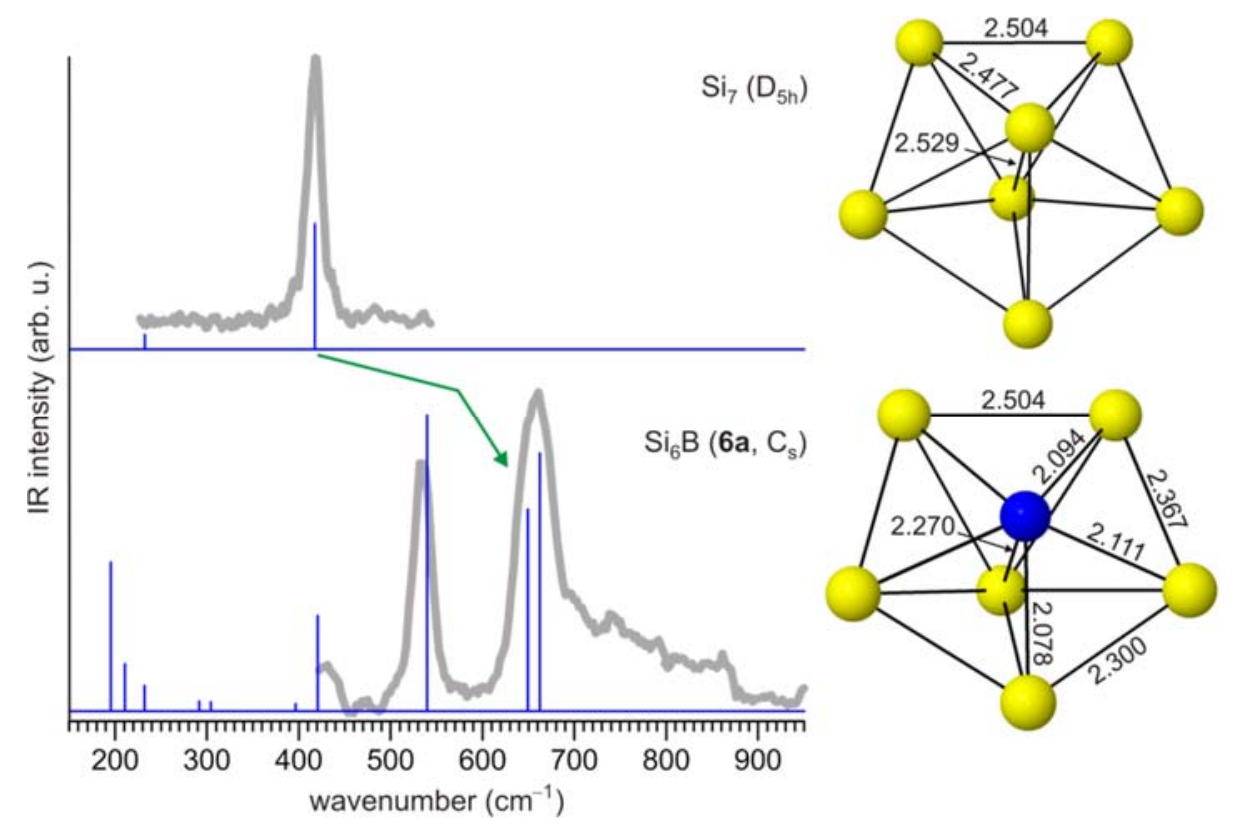

Figure 5. Ground state structures and IR spectra of $\mathrm{Si} 7\left(\mathrm{D}_{5 h}\right)$ and $\mathrm{Si} 6 \mathrm{~B}\left(\mathrm{C}_{\mathrm{s}}\right)$ clusters calculated at the TPSS-D3 level compared to the IR-UV2Cl spectra. The green arrow marks the shift and splitting of the degenerate axial bending mode when a Si atom is substituted by a B atom in the $\mathrm{Si}_{7}$ cluster. Bond lengths are given in $\AA$. 